\title{
Farklı Demleme Yöntemlerinin Soğuk Hibiskus Çayının Bazı Fiziksel ve Biyoaktif Özellikleri Üzerine Etkisi
}

\author{
Vildan EYİZ, İsmail TONTUL ${ }^{1 *}(\mathbb{0})$ \\ ${ }^{1}$ Necmettin Erbakan Üniversitesi, Mühendislik ve Mimarlık Fakültesi, Gıda Mühendisliği Bölümü, 42090, \\ Konya
}

Geliş / Received: 08/04/2020, Kabul / Accepted: 30/05/2020

\section{Öz}

Hibiscus sabdariffa L., çiçek tomurcukları yüksek antosiyanin içeriğine sahip bir bitkidir. Bu bitkilerden elde edilen çeşitli ekstraktlar, geleneksel tıpta yüksek tansiyon, karaciğer hastalıkları ve ateş gibi birçok hastalıkta karşı kullanılmaktadır. Bitkinin en yaygın tüketimi, kurutulmuş çiçek tomurcuklarının demlenmesi sonrasında soğuk veya sıcak çay olarak tüketilmesidir. Bu çalışmada farklı demleme yöntemlerinin elde edilen soğuk çayın renk [L* (27.9-33.3), $\mathrm{a}^{*}$ (45.5-48.4), $\mathrm{b}^{*}$ (26.4-33.6)] ve biyoaktif özellikleri [toplam fenolik madde miktarı (647.7-1184.4 mg GAE/L), DPPH radikalini indirgeme aktivitesi (752.7-1178.5 mg TE/L), toplam flavonoid miktarı (55.2-84.4 mg CE/L) ve toplam monomerik antosiyanin miktarı (1291.7-2372.1 mg S3G/L)] etkileri araştırılmıştır. Bu amaçla soğuk, sıcak ve mikrodalga demleme dahil olmak üzere 6 farklı demleme yöntemi kullanılmıştır. Çalışma sonucunda, demleme yönteminin, hibiskus çayının renk değerleri üzerine önemli etkisi olduğu görülmüsşür. Sicak demleme ve mikrodalga demleme + buz uygulaması en yüksek $L^{*}, a^{*}$ ve $b^{*}$ değerlerinin eldesine neden olmuştur. Biyoaktif özellikler açısından değerlendirildiğinde en yüksek değerlerin mikrodalga demleme yöntemi ile elde edildiği tespit edilmiştir. Çalışmada elde edilen bulgulara göre hem işlem süresinin kısa olması hem de daha iyi biyoaktif özelliklere sahip olması nedeniyle mikrodalga demlemenin kullanılması önerilmektedir.

Anahtar Kelimeler: Hibiskus, antosiyanin, flavonoid, antioksidan, fenolik

\section{The Effect of Different Brewing Methods on Some Physical and Bioactive Properties of Cold Hibiscus} Tea

\begin{abstract}
Hibiscus sabdariffa L. is a plant that have a high anthocyanin content in flower buds. Various extracts of the herbs are used in traditional medicine against many diseases such as high blood pressure, liver diseases and fever. The most common consumption of the plant is consuming as cold or hot tea after the infusion of dried flower buds. In this study, color [ $\mathrm{L}^{*}(27.9-33.3), \mathrm{a}^{*}(45.5-48.4), \mathrm{b}^{*}$ (26.4-33.6)] and some bioactive [total phenolic content (647.7-1184.4 mg GAE/L), DPPH radical scavenging activity (752.7-1178.5 mg TE/L), total flavonoid content (55.2-84.4 mg CE/L) and total monomeric anthocyanin content (1291.7-2372.1 mg C3G/L)] properties of teas obtained from different brewing methods were determined. For this purpose, 6 different brewing methods were used including cold, hot and microwave brewing. As a result of the study, it was determined that the brewing method had an important effect on the color values of hibiscus tea. Hot brewing and microwave brewing + ice application caused the highest $\mathrm{L}^{*}, \mathrm{a}^{*}$ and $\mathrm{b}^{*}$ values. In terms of bioactive properties, microwave brewing method yielded the best results. According to the data obtained in the study, it is recommended to use microwave brewing because it provided a short processing time and better bioactive properties.
\end{abstract}

Keywords: Hibiscus, anthocyanin, flavonoid, antioxidant, phenolic 


\section{Giriş}

Hibiscus sabdariffa L., farklı yörelerde hibiskus, roselle, nar çiçeği, bamya çiçeği, bissap ve kerkede olarak bilinen Malvaceae familyasından bir bitkidir (Chang vd., 2006; Ismail vd., 2008; Lin vd., 2007). Bitki, tropikal ve subtropikal bölgelerde yetiştirilmektedir (Mahadevan ve Kamboj, 2009). Hibiskus yaklaşı 3-3.5 m boyunda ve kazık köke sahip bir bitkidir. Hibiskusun yaprakları 7.5-12.5 cm uzunluğunda, yeşil, kırmızıms1 renklerde ve damarlıdır. Yapraklar, düz, silindirik kırmızı saplar üzerinde sıralı bir şekilde dizilmişlerdir. Çiçekler, gül veya kestane renginde ve kurudukça renkleri pembeye dönmektedir (Mahadevan and Kamboj, 2009). Hibiskus cinsinin dünya genelinde 500 'den fazla türü olduğu bildirilmektedir (Cid-Ortega and Guerrero-Beltrán, 2015). Ticari potansiyele sahip en önemli türler Hibiscus sabdariffa $\mathrm{L}$. var. altissima Wester ve ikincisi Hibiscus sabdariffa var. sabdariffa'dır (Christian and Jackson, 2009).

Günümüzde tüketiciler, sağlıklı beslenmeye ve tıbbi özelliklere sahip yiyeceklere büyük ilgi göstermektedirler (Zannou vd., 2020). Parlak kırmızı renkte ve eşsiz lezzette olan hibiskus değerli bir gida ürünüdür. Genellikle reçel, marmelat, içecek (sıcak ve soğuk içecekler ve fermente içecekler), şarap, jöleli şekerlemeler, dondurma, çikolatalar, lezzet verici ajanlar, pudingler, kekler ve süt ürünlerinin üretiminde renklendirici ve aroma verici olarak kullanılmaktadır (Tsai vd., 2002). Ayrica hibiskusun iyi bir polifenol, antioksidan ve antosiyanin kaynağı olduğu pek çok çalı̧̧ma ile bildirilmiştir (Abdullakasim vd., 2007; Christian ve Jackson, 2009; Leyva Daniel vd., 2013;
Segura-Carretero vd., 2008; Sinela vd., 2017). $\mathrm{Bu}$ özellikleri nedeniyle hibiskusun beslenme açısında önemi gün geçtikçe artmaktadır.

Hibiskusun sağlık üzerine faydalı etkileri pek çok çalışma ile ortaya koyulmuştur. Faraji and Tarkhani (1999), hibiskusun hipertansiyonu engelleyici etkilerinin olduğunu bildirmiştir Mahadevan ve Kamboj (2009) hibiskus çayının ürik asitin atılımını sağlayan etkisi olduğu rapor edilmiştir. McKay vd. (2009) yaptıkları bir çalışmada hibiskus çayı tüketiminin antihipertansif etkilerini incelemişlerdir. Kan basıncı düşürücü ilaçları kullanmayan, 30-70 yaş arası 65 hipertansif yetişkinlerde gerçekleştirilen kontrollü deneyde günlük olarak hibiskus çayı tüketiminin hipertansif yetişkinlerde kan basıncını etkili bir şekilde düşürdüğünü gözlemlemişlerdir.

Demleme metotlarının bitkisel çayların biyoaktif özellikleri üzerine etkisini araştırmak amacıyla bir dizi çalışma yürütülmüştür. Damiani vd. (2014) çalışmalarında, beyaz çayın toplam fenolik, antioksidan aktivite, flavonoid ve kateşin içeriğine demleme metotlarının etkisi araştırmışlardır. Beyaz çay hem oda sicaklı̆ğında $\left(20-25{ }^{\circ} \mathrm{C} 2\right.$ saat $)$ hem de sicak demleme $\left(70{ }^{\circ} \mathrm{C} 7\right.$ dakika) yöntemleri ile hazırlanmıştır. Oda sıcaklığında 2 saat demleme ile hazırlanan çayların özellikle antioksidan aktivite olmak üzere flavonoid, toplam fenolik madde ve kateşin içeriğinin sıcak demleme yöntemine oranla daha yüksek olduğu belirtilmiştir. Yapılan başka bir çalışmada, kısa bir sıcak demleme basamağının ardından buz ilavesinin ürünün özellikleri üzerine etkisi değerlendirilmiştir. $\mathrm{Bu}$ yöntem sıcak ve soğuk demlenmeyle karşılaştırılarak yeşil, siyah ve oolong 
çaylarındaki etkisini incelemek üzere kateşinler, ksantinler ve gallik asit içeriği, antioksidan aktivite, toplam fenolik madde miktarı ve renk analizleri gerçekleştirilmiştir. Sicak demleme ile hızlı ekstraksiyon sağlansa da bileşenler degrade olurken bunun aksine soğuk demlemede yavaş ekstraksiyon ile bileşenler korunmuştur. Buzlu demleme ile, kısa sürede, soğuk demleme ile benzer antioksidan aktivite sağlandiğ (Lantano vd., 2015). Ancak farklı demleme koşullarının hibiskus çayı özellikleri üzerine etkilerinin araştırıldığı yalnızca bir çalışmaya ulaşılmıştır (Zannou vd., 2020). Bu çalışmada, sicak $\left(98^{\circ} \mathrm{C}\right.$ 'de 16 veya $\left.40 \mathrm{dk}\right)$ ve soğuk (oda sicaklığında 24 saat) demlenmiş çayların renk, $\mathrm{pH}$, toplam fenolik madde miktarı, antioksidan kapasitesi ve aroma aktif bileşenleri analiz edilmiştir.

Yapılan bu çalışmada hibiskus yaprağından farklı demleme metotları kullanılarak elde dilen hibiskus çaylarının renk, toplam fenolik madde miktarı, DPPH radikalini indirgeme aktivitesi, toplam flavonoid miktarı ve toplam monomerik antosiyanin miktarı üzerine etkisi belirlenmiştir. Çalışmanın sonuçlarından yola çıkarak hibiskus çayı için en uygun demleme metodunun belirlenmesi amaçlanmıştır.

\section{Materyal ve Metot}

\subsection{Materyal}

Materyal olarak kullanılan kurutulmuş hibiskus çiçeği ticari olarak Konya ilinde bir aktardan temin edilmiştir. Ürün Kraft

torbalarda oda sıcaklığında depolanmıştır. Analizlerde kullanılan kimyasallar Merck (Almanya) firmasından temin edilmiştir.

\subsection{Metot}

\subsubsection{Demleme yöntemleri}

Satın alınan kuru hibiskus çiçekleri bir blenderda parçalanmış ve $1 \mathrm{~mm}$ elekten elendikten sonra demleme işlemlerinde kullanılmıştır. Hibiskus çayları hazırlanırken 6 farklı demleme metodu kullanılmıştır. Kullanılan demleme metotları Tablo 1'de gösterilmiştir Tüm çalışmalar $25^{\circ} \mathrm{C}$ 'ye koşullandırılmış oda koşullarında gerçekleştirilmiştir. Mikrodalga demleme işlemleri LG marka (SolarDOM ${ }^{\mathrm{TM}}$, Seul, Güney Kore) mikrodalga fırın kullanılmıştır. Demleme işlemlerinden sonra ekstraktlar filtre kağıdından süzülerek posa uzaklaştırılmıştır. Ekstraktlar hazırlandıktan sonra $4^{\circ} \mathrm{C}$ 'de depolanmış ve aynı gün içerisinde tüm analizleri tamamlanmıştır.

\subsubsection{Renk analizi}

Örneklerin renk değerleri Konica Minolta CR400 renk ölçer (Tokyo, Japonya) ile ölçülerek, L*, a* ve $b^{*}$ değerleri cinsinden kaydedilmiştir. Bu amaçla $20 \mathrm{~mL}$ ekstrakt sıvı ölçüm kabına aktarılmış ve her bir örnek için 10 farklı ölçüm alınmıştır.

\subsubsection{Toplam fenolik madde miktarı}

Tablo 1. Demleme koşulları

\begin{tabular}{ll}
\hline Demleme yöntemi & Uygulama \\
\hline Sıcak demleme & $2 \mathrm{~g}$ hibiskus $90{ }^{\circ} \mathrm{C}$ sıcaklıktaki saf su ile $100 \mathrm{~mL}$ 'ye tamamlanmış ve oda \\
& Sicaklığına kadar kendi kendine soğuması beklenmiştir. \\
Soğuk demleme (oda sıcaklığında) & $2 \mathrm{~g}$ hibiskus oda sıcaklığındaki saf su ile $100 \mathrm{~mL}$ 'ye tamamlanmış ve 120 \\
& $\mathrm{dk}$ demlenmiştir. \\
& $2 \mathrm{~g}$ hibiskus $4{ }^{\circ} \mathrm{C}$ sıcaklıktaki saf su ile $100 \mathrm{~mL}$ 'ye tamamlanmış ve 12 \\
Soğuk demleme $\left(4^{\circ} \mathrm{C}\right)$ & saat demlenmiştir. \\
& $2 \mathrm{~g}$ hibiskus $90{ }^{\circ} \mathrm{C}$ sıcaklıktaki $58 \mathrm{~mL}$ saf su ile $60 \mathrm{~mL}$ 'ye tamamlanmış \\
Sıcak demleme + buz & ve 7 dk beklendikten sonra içerisine $40 \mathrm{~g}$ buz ilave edilerek soğutulmuştur. \\
& $2 \mathrm{~g}$ hibiskus oda sıcaklığındaki saf su ile $100 \mathrm{~mL}$ 'ye tamamlanmış ve \\
Mikrodalga demleme & $360 \mathrm{~W}$ güçte çalışan mikrodalga firında $7 \mathrm{dk}$ tutulmuştur. \\
& $2 \mathrm{~g}$ hibiskus $90^{\circ} \mathrm{C}$ sıcaklıktaki $58 \mathrm{~mL}$ saf su ile $60 \mathrm{~mL}$ 'ye tamamlanmış \\
Mikrodalga demleme + buz & ve $360 \mathrm{~W}$ güçte çalışan mikrodalga firında $7 \mathrm{dk}$ tutulmuştur. Süre sonunda \\
& ekstrakt içerisine $40 \mathrm{~g}$ buz ilave edilerek soğutulmuştur.
\end{tabular}


Örneklerin toplam fenolik madde miktarı spektrofotometrik yöntemle belirlenmiştir. $\mathrm{Bu}$ amaçla öncelikle ön denemeler gerçekleştirilerek uygun seyreltme oranları belirlenmiştir. Daha sonra seyreltilmiş örneklerden $0.5 \mathrm{~mL}$ alınarak üzerine $2 \mathrm{~mL}$ Folin-Cioceltau çözeltisi $(0,2 \mathrm{~N})$ ve $2,5 \mathrm{~mL}$ sodyum karbonat çözeltisi $(\% \mathbf{7 , 5 )}$ ilave edilerek karıştırılmıştır. Bu sırada örnek yerine saf su içeren körde hazırlanmıştır. Tüm örnekler 5 dakika $50{ }^{\circ} \mathrm{C}$ su banyosunda (Nüve, Ankara, Türkiye) bekletilmiş ve daha sonra oda sıcaklığına kadar soğuması beklenmiştir. Örneklerin absorbansı $760 \mathrm{~nm}$ dalga boyunda köre karşı spektrofotometrede (Biochrom Libra S22, ABD) kaydedilmiştir. Örneklerin toplam fenolik madde miktarı gallik asit ile hazırlanan kurveye göre toplam fenolik madde miktarları mg gallik asit eşdeğeri (GAE)/L cinsinden hesaplanmıştır (Tontul and Topuz, 2017).

\subsubsection{DPPH radikalini indirgeme aktivitesi}

DPPH radikalini indirgeme aktivitesi Tontul ve Topuz (2017) tarafindan bildirilen yöntemle belirlenmiştir. Uygun oranda seyreltilmiş örneklerden $0,05 \mathrm{~mL}$ alınarak üzerine 0,95 mL DPPH çözeltisi (metanolde hazırlanmış $60 \quad \mu \mathrm{M})$ ilave edilerek karıştırılmıştır. 30 dakika karanlıkta bekletilen örneklerin absorbans1, örnek yerine saf su ile hazırlanan köre karșı spektrofotometre $517 \mathrm{~nm}$ 'de okunmuştur. Elde edilen absorbans değerleri kullanılarak trolox (6-hydroxy-2,5,7,8tetramethylchroman-2-carboxylic acid) ile hazırlanan kurveye göre DPPH radikalini indirgeme aktivitesi $\mathrm{mg}$ trolox eşdeğeri (TE)/L olarak belirlenmiştir (Tontul and Topuz, 2017).

\subsubsection{Toplam flavonoid miktarı}

Toplam flavonoid miktarını belirlemek amaciyla $0.5 \mathrm{~mL}$ ekstrakt üzerine $2.5 \mathrm{~mL}$ saf su ve $150 \mu \mathrm{L} \mathrm{NaNO}_{2}$ (\%5) çözeltisi ilave edilerek karıştırılmış ve oda sıcaklığında 5 dakika bekletilmiştir. Daha sonra, $300 \mu \mathrm{L}$ $\mathrm{AlCl}_{3}$ (\%10) eklenmiş ve karıştırılarak tekrar 5 dakika bekletilmiştir. Son olarak $1 \mathrm{~mL}$ $\mathrm{NaOH}(1 \mathrm{M})$ ve $0.55 \mathrm{~mL}$ saf su ilave edilerek karıştırılmıştır. Numune ile hazırlanan çözeltinin absorbansı, örnek yerine saf su ile hazırlanan köre karş1 510 nm'de ölçülmüştür. Sonuçlar kateşin ile hazırlanan kurve yardımıyla mg kateşin eşdeğeri (CE)/L cinsinden hesaplanmıştır (Chang vd., 2006).

\subsubsection{Toplam monomerik antosiyanin miktarı}

Örneklerin toplam monomerik antosiyanin miktarları $\mathrm{pH}$ diferansiyel metodu ile belirlenmiştir. $\mathrm{Bu}$ amaçla örnekler, uygun oranda potasyum klorür tampon çözeltisi ( $\mathrm{HCl}$ ile $\mathrm{pH} 1$ 'e ayarlanmış $0.025 \mathrm{M}$ ) ve sodyum asetat tampon çözeltisi $(\mathrm{HCl}$ ile $\mathrm{pH}$ 4'e ayarlanmış $0.4 \mathrm{M}$ ) seyreltilmiştir. Her iki seyreltik, karanlıkta $20 \mathrm{dk}$ bekletildikten sonra absorbanslar1 510 ve $700 \mathrm{~nm}$ dalga boyundaki absorbansları ölçülmüştür. Sonuçlar Cemeroğlu (2007) tarafindan bildirilen şekilde $\mathrm{mg}$ syanidin-3-glukozit (S3G)/L cinsinden hesaplanmıştır.

\subsection{7. İstatistiksel analizler}

Üretimler iki tekerrürlü, analizler paralelli olarak gerçekleştirilmiştir. Elde edilen veriler varyans analizi ve Duncan Çoklu Karşılaştırma testine tabi tutulmuştur. İstatiksel analizler SAS programı ile yapılmıştır. 
Tablo 2. Analiz edilen parametreler arası korelasyon

\begin{tabular}{|c|c|c|c|c|c|c|}
\hline Analizler & $\mathbf{L}$ & $\mathbf{a}$ & b & $\begin{array}{l}\text { Toplam } \\
\text { fenolik } \\
\text { madde } \\
\text { miktarı }\end{array}$ & $\begin{array}{c}\text { DPPH } \\
\text { radikalini } \\
\text { indirgeme } \\
\text { aktivitesi }\end{array}$ & $\begin{array}{c}\text { Toplam } \\
\text { flavonoid } \\
\text { miktarı }\end{array}$ \\
\hline $\mathbf{a}$ & $\begin{array}{c}0.630 \\
(-0.028)\end{array}$ & & & & & \\
\hline b & $\begin{array}{c}0.920 \\
(0,000)\end{array}$ & $\begin{array}{c}0.716 \\
(0.009)\end{array}$ & & & & \\
\hline $\begin{array}{l}\text { Toplam fenolik madde } \\
\text { miktarı }\end{array}$ & $\begin{array}{l}-0.728 \\
(0.007)\end{array}$ & $\begin{array}{l}-0.065 \\
(0.841)\end{array}$ & $\begin{array}{l}-0.677 \\
(0.016)\end{array}$ & & & \\
\hline $\begin{array}{l}\text { DPPH radikalini } \\
\text { indirgeme aktivitesi }\end{array}$ & $\begin{array}{l}-0.759 \\
(0.004)\end{array}$ & $\begin{array}{l}-0.124 \\
(0.700)\end{array}$ & $\begin{array}{l}-0.710 \\
(0.010)\end{array}$ & $\begin{array}{c}0.991 \\
(0.000)\end{array}$ & & \\
\hline $\begin{array}{l}\text { Toplam flavonoid } \\
\text { miktarı }\end{array}$ & $\begin{array}{l}-0.482 \\
(0.113)\end{array}$ & $\begin{array}{c}0.063 \\
(0.845)\end{array}$ & $\begin{array}{l}-0.448 \\
(0.144)\end{array}$ & $\begin{array}{c}0.816 \\
(0.001)\end{array}$ & $\begin{array}{c}0.802 \\
(0.002)\end{array}$ & \\
\hline $\begin{array}{l}\text { Toplam monomerik } \\
\text { antosiyanin miktarı }\end{array}$ & $\begin{array}{l}-0.764 \\
(0.004)\end{array}$ & $\begin{array}{l}-0.192 \\
(0.55)\end{array}$ & $\begin{array}{l}-0.766 \\
(0.004)\end{array}$ & $\begin{array}{c}0.971 \\
(0.000)\end{array}$ & $\begin{array}{c}0.986 \\
(0.000)\end{array}$ & $\begin{array}{c}0.786 \\
(0.002)\end{array}$ \\
\hline
\end{tabular}

Parantez içerisindeki değer $\mathrm{p}$ değerini göstermektedir.

\section{Bulgular ve Tartışma}

Farklı demleme yöntemleri ile elde edilmiş hibiskus çaylarına ait renk, toplam fenolik madde miktarı, DPPH radikalini indirgeme aktivitesi, toplam flavonoid miktarı ve toplam monomerik antosiyanin miktarı arasındaki korelasyon tablosu Tablo 2'de verilmiştir.

\subsection{Renk}

Farklı demleme metotları kullanılarak hazırlanan hibiskus çaylarına ait renk değeri sonuçları Tablo 3'de verilmiştir. Örneklere ait $\mathrm{L}^{*}$ değerleri 27.9-33.3 arasında, a* değerleri 45.0-48.3 arasında, $b^{*}$ değerleri 27.0-34.0 arasında değişim göstermiştir (Tablo 3). Elde edilen sonuçlara göre en yüksek $L^{*}$ değerleri sicak demleme, oda sicaklığında soğuk demleme ve mikrodalga demleme + buz uygulamasında gözlenmiştir. Dolayısıyla bu demleme yöntemlerinin daha parlak bir ekstrakt oluşuma imkan verdiği söylenebilir. Genel olarak değerlendirildiğinde ekstraktların a* değerlerinin dar bir aralıkta değişim gösterdiği söylenebilir. Nitekim Duncan Çoklu Karşılaştırma Testi sonuçları yalnızca mikrodalga demleme + buz uygulaması ile $+4^{\circ} \mathrm{C}$ 'de soğuk demleme arasında önemli bir farklılık tespit edilmiş, diğer tüm demleme yöntemleri ile demlenen çaylar bu uygulamalara istatistiki olarak benzer $a^{*}$ değerine sahip olmuştur. Örneklerin $b^{*}$ değerleri ile L değerleri arasında önemli korelasyon tespit edilmiştir.

\subsection{Toplam fenolik madde analizi}

Altı farklı demleme metodu ile hazırlanmış hibiskus çaylarının toplam fenolik madde miktarları 647.7-1184.4 mg GAE/L arasında değişim göstermiştir (Tablo 4). Mikrodalga ile demlenen çaylar en yüksek fenolik madde miktarına sahip iken, en düşük fenolik madde

Tablo 3. Farklı demleme metotları kullanılarak hazırlanan hibiskus çaylarına ait $L^{*}, a^{*}$ ve $b^{*}$ değerleri

\begin{tabular}{lccc}
\hline Demleme metotları & $\mathbf{L}^{*}$ & $\mathbf{a}^{*}$ & $\mathbf{b}^{*}$ \\
\hline Sicak demleme & $33.3 \pm 0.0^{\mathrm{a}}$ & $46.8 \pm 1.2^{\mathrm{ab}}$ & $33.6 \pm 0.8^{\mathrm{a}}$ \\
Soğuk demleme (oda sicaklığı) & $32.1 \pm 0.9^{\mathrm{a}}$ & $47.9 \pm 0.7^{\mathrm{ab}}$ & $31.4 \pm 0.5^{\mathrm{ab}}$ \\
Soğuk demleme $\left(4^{\circ} \mathrm{C}\right)$ & $27.9 \pm 0.3^{\mathrm{c}}$ & $45.5 \pm 0.1^{\mathrm{b}}$ & $28.1 \pm 0.7^{\mathrm{cd}}$ \\
Sicak demleme + buz & $29.7 \pm 0.7^{\mathrm{b}}$ & $47.6 \pm 0.5^{\mathrm{ab}}$ & $30.3 \pm 1.0^{\mathrm{bc}}$ \\
Mikrodalga demleme & $28.0 \pm 0.1^{\mathrm{bc}}$ & $45.9 \pm 0.8^{\mathrm{ab}}$ & $26.4 \pm 1.1^{\mathrm{d}}$ \\
Mikrodalga demleme + buz & $32.1 \pm 0.2^{\mathrm{a}}$ & $48.4 \pm 0.1^{\mathrm{a}}$ & $33.1 \pm 0.3^{\mathrm{a}}$ \\
\hline
\end{tabular}

Sonuçlar ortalama \pm standart hata olarak verilmiştir. Farklı harfle işaretlenmiş aynı sütundaki ortalamalar istatistiki olarak birbirinden farklıdır $(\mathrm{p}<0,05)$. 
miktarı sıcak demleme yöntemi ile elde edilen çaylarda belirlenmiştir. Diğer demleme yöntemleri ile üretilen çayların toplam fenolik madde içeriğinin istatistiksel olarak benzer olduğu tespit edilmiştir. Çalışmada belirlenen sonuçlara benzer şekilde, Damiani vd. (2014) soğuk demleme ile hazırlanan beyaz çayların sıcak demlemeye kıyasla daha yüksek toplam fenolik madde içeriğine sahip olduğunu bildirmiştir. Ancak Zannou vd. (2020) hibiskus çayı için tam tersi sonuçlar rapor etmişlerdir. Nitekim sıcak demlenmiş hibiskus çayının toplam fenolik madde miktar1 2135-2201 mg GAE/L, oda sıcaklığında soğuk demlenmiş çayların toplam fenolik madde miktarı ise $1556 \mathrm{mg}$ GAE/L olarak belirlenmiştir. $\mathrm{Bu}$ durumun uygulanan süre demleme süreleri, bitkiye uygulanan ön işlemler ve demleme sıcaklıklarındaki farklılıktan kaynaklandığı düşünülmektedir.

Mikrodalga demleme ile elde edilen çayların fenolik madde miktarının daha yüksek bulunmasının nedeninin hızlı 1sıtma sağlamasından ve bitki içerisindeki polar karakterli bileşenlerde titreşime neden olarak difüzyon hızını arttırmasından kaynaklandığı düşünülmektedir. Yapılan bir çalışmada, mikrodalga firında siyah çay demlenerek fenolik bileşik miktarı geleneksel demleme yöntemi ile karşılaştırmalı olarak analiz edilmiştir. Mikrodalga demlemenin ekstraktların antioksidan potansiyelini değiştirmeden, geleneksel demleme tekniğine kıyasla daha yüksek geri kazanımlara izin verdiği ortaya koyulmuştur (Spigno and De Faveri, 2009).

\subsection{DPPH radikalini indirgeme aktivitesi}

Farklı demleme yöntemleri ile elde edilen hibiskus çaylarının DPPH radikalini indirgeme aktivitesi 752.7-1178.5 g TE/L arasında belirlenmiştir (Tablo 4). Tablo 1'de verilen korelasyon verilerinden anlaşıldı $\breve{g}_{1}$ gibi, DPPH radikalini indirgeme aktivitesi ile toplam fenolik madde miktarı arasında yüksek bir ilişki tespit edilmiştir. $\mathrm{Bu}$ nedenle en yüksek DPPH radikalini indirgeme aktivitesi mikrodalga ile demlenen hibiskus çaylarında gözlenmiştir. Ayrıca en düşük DPPH radikalini indirgeme aktivitesinin sicak demleme ile hazırlanmış çaylara ait olduğu, diğer 4 demleme yöntemi arasında ise önemli bir farklılığın bulunmadığı tespit edilmiştir. Mikrodalga demlemenin daha yüksek DPPH radikalini indirgeme aktivitesi sağlama nedeninin dielektrik isıtma ile enerji transferinin hızlanmasının ve çözücünün matrise nüfuz etmesinin kolaylaşması olduğu değerlendirilmektedir (Damiani vd., 2019).

Çalışma bulgularına benzer şekilde, soğuk ve sıcak demlenmiş beyaz çayların ABTS

Tablo 4. Farklı demleme metotları kullanılarak hazırlanan hibiskus çaylarına ait biyoaktif özellikleri

\begin{tabular}{|c|c|c|c|c|}
\hline Demleme metotları & $\begin{array}{c}\text { Toplam } \\
\text { fenolik madde } \\
\text { miktarı (mg } \\
\text { GAE/L) }\end{array}$ & $\begin{array}{l}\text { DPPH radikalini } \\
\text { indirgeme } \\
\text { aktivitesi (mg } \\
\text { TE/L) }\end{array}$ & $\begin{array}{c}\text { Toplam } \\
\text { flavonoid } \\
\text { miktarı } \\
\text { (mg CE/L) }\end{array}$ & $\begin{array}{c}\text { Toplam } \\
\text { monomerik } \\
\text { antosiyanin } \\
\text { miktarı (mg } \\
\text { S3G/L) }\end{array}$ \\
\hline Sicak demleme & $647.7 \pm 94.7^{\mathrm{c}}$ & $752.7 \pm 86.3^{\mathrm{c}}$ & $55.2 \pm 4.0^{\mathrm{d}}$ & $1291.7 \pm 201.2^{\mathrm{c}}$ \\
\hline Soğuk demleme (oda sıcaklığı) & $840.7 \pm 2.7^{\mathrm{b}}$ & $894.7 \pm 10.5^{b}$ & $63.3 \pm 0.8^{\mathrm{cd}}$ & $1688.3 \pm 53.4^{\mathrm{b}}$ \\
\hline Soğuk demleme $\left(4^{\circ} \mathrm{C}\right)$ & $908.3 \pm 2.1^{\mathrm{b}}$ & $973.7 \pm 4.0^{\mathrm{b}}$ & $67.3 \pm 0.3^{\mathrm{cd}}$ & $1811.8 \pm 10.0^{\mathrm{b}}$ \\
\hline Sicak demleme + buz & $1017.3 \pm 15.4^{\mathrm{ab}}$ & $1031 \pm 12.9^{b}$ & $70.0 \pm 1.0^{\mathrm{bc}}$ & $1935.4 \pm 13.4^{\mathrm{b}}$ \\
\hline Mikrodalga demleme & $1184.4 \pm 60.1^{\mathrm{a}}$ & $1178.5 \pm 16.9^{\mathrm{a}}$ & $84.4 \pm 3.9^{\mathrm{a}}$ & $2372.1 \pm 34.2^{\mathrm{a}}$ \\
\hline Mikrodalga demleme + buz & $908.3 \pm 39.4^{\mathrm{b}}$ & $957.6 \pm 42.7^{\mathrm{b}}$ & $80.0 \pm 5.8^{\mathrm{ab}}$ & $1745.0 \pm 60.1^{\mathrm{b}}$ \\
\hline
\end{tabular}


yöntemi ile belirlenmiş antioksidan aktivitesinin karşılaştırıldığı bir çalışmada soğuk demlenmiş çayların antioksidan aktivitesi sıcak demlenmiş çaylara göre daha yüksek olarak belirlenmiştir (Damiani vd., 2014). Zit şekilde, hibiskus çayı ile gerçekleştirilen bir çalışmada ise sıcak demlenmiş çayların antioksidan aktivitesinin soğuk demlenmiş çaylara kıyasla önemli düzeyde yüksek olduğu bildirilmiştir (Zannou vd., 2020). Ancak rooibos çayı ile gerçekleştirilen bir çalışmada, fermente edilmiş çaylarda sıcak demleme $\left(100^{\circ} \mathrm{C}\right.$ 'de 5 $\mathrm{dk}$ ); fermente edilmemiş çaylarda ise soğuk demleme daha yüksek antioksidan aktivite sağlamıştır (Damiani vd., 2019). Bu nedenle, literatür ve mevcut çalışma bulgularındaki farklılığın hammadde ve demleme koşullarından kaynaklandiğı düşünülmüştür.

\subsection{Toplam flavonoid miktarı}

Farklı demleme yöntemleri ile hazırlanmış hibiskus çaylarının flavonoid miktarları 55.2 ile $84.4 \mathrm{mg} / \mathrm{L}$ arasında değişim göstermiştir (Tablo 4). Toplam flavonoid miktarı ile analiz edilen tüm biyoaktif özellikler arasında iyi bir korelasyon tespit edilmiştir (Tablo 2). En yüksek toplam flavonoid miktarı mikrodalga ile demlenmiş çaylarda belirlenmiş ve bunu mikrodalga demleme + buz uygulaması takip etmiştir. Sıcak demleme yöntemi ile hazırlanmış olan çaylar en düşük flavonoid miktarına sahip olmuştur. Benzer şekilde, bambu filiz ekstraktı ile yapılan bir çalışmada mikrodalga destekli ekstraksiyonda (4 dk), oda sıcaklığında 24 saatlik soğuk demlemeye göre 1,6 kat daha yüksek toplam flavonoid miktarı rapor edilmiştir (Milani vd., 2020).

\subsection{Toplam monomerik antosiyanin}

Hibiskus bitkisi iyi bir antosiyanin kaynağıdır. Elde edilen sonuçlara göre hibiskus çaylarının toplam monomerik antosiyanin miktarı
1291.7 ile $2372.1 \quad \mathrm{mg} \quad \mathrm{S} 3 \mathrm{G} / \mathrm{L}$ arasında belirlenmiştir. Diğer biyoaktif özelliklere paralel şekilde mikrodalga demleme en yüksek toplam monomerik antosiyanin miktarı sağlarken, en düşük toplam monomerik antosiyanin miktarı sıcak demleme ile hazırlanmış çaylarda tespit edilmiştir. Diğer demleme yöntemleri ile hazırlanan çayların toplam monomerik antosiyanin miktarı istatistiksel olarak benzer bulunmuştur. Yapılan birçok çalışmada mikrodalga ekstraksiyonla elde edilen ekstraktların toplam monomerik antosiyanin miktarının konvansiyonel ekstraksiyon yöntemleri ile elde edilenlere göre daha yüksek olduğu rapor edilmiştir (Sun vd., 2007; Yang ve Zhai, 2010). Bu durumun mikrodalga etkisi ile bitki dokusunda bölgesel sıcaklık artışı meydana gelmesine ve bu nedenle hücre yapısında bozulmaya neden olmasından kaynaklandığ değerlendirilmiştir. Hücre yapısında meydana gelen bu bozulma etkisiyle antosiyanin ekstraksiyonu hızlanmaktadır.

\section{Sonuç}

Hibiskus parlak kırmızı rengi ve eşsiz lezzeti nedeniyle genellikle reçel, marmelat, sicak ve soğuk içecek yapımında kullanılmaktadır. İçerdiği biyoaktif bileşenler nedeniyle antioksidan aktivite, aterosklerozdan korunma ve antikarsinojenik aktivite gibi biyolojik aktivitesi bulunmaktadır. Yapılan bu çalışmada soğuk hibiskus çay üretimi için araştırılan demleme yöntemleri içerisinde en uygun demleme yönteminin ortaya konulması amaçlanmıştır. Çalışma sonuçları değerlendirildiğinde mikrodalga ile demlenmiş çayların daha yüksek biyoaktif özelliklere sahip olduğu belirlenmiştir. Mikrodalga demleme + buz uygulamasında ise daha düşük değerler elde edilmiştir. $\mathrm{Bu}$ durumun ekstraksiyon sırasında daha düşük 
olan sıv1-katı oranından kaynaklandığı değerlendirilmektedir. Sicak demleme yöntemi ile hazırlanan çaylar ise en düşük biyoaktif özelliklerin eldesine yol açmıştır. Bu nedenle sicak demleme sirasinda biyoaktif bileşenlerde $1 \mathrm{~s} 1$ etkisi ile degradasyon meydana gelmiştir. $\mathrm{Bu}$ çalışmanın, son zamanlarda artan bitkisel çay tüketimi nedeniyle gelecekteki biyolojik araştırmalara ve endüstriyel uygulamalara önemli ölçüde 1şık tutacağı düşünülmektedir.

\section{Kaynaklar}

Abdullakasim, P., Songchitsomboon, S., Techagumpuch, M., Balee, N., Swatsitang, P., \& Sungpuag, P. (2007). "Antioxidant capacity, total phenolics and sugar content of selected Thai health beverages", International journal of food sciences and nutrition, 58(1), 77-85.

Cemeroğlu, B. (2007). "Gıda analizleri"). Ankara: Gıda Teknolojisi Derneği Yayınları.

Chang, Y.-C., Huang, K.-X., Huang, A.-C., Ho, Y.-C., \& Wang, C.-J. (2006). "Hibiscus anthocyanins-rich extract inhibited LDL oxidation and oxLDL-mediated macrophages apoptosis", Food and Chemical Toxicology, 44(7), 1015-1023.

Christian, K. R., \& Jackson, J. C. (2009). "Changes in total phenolic and monomeric anthocyanin composition and antioxidant activity of three varieties of sorrel (Hibiscus sabdariffa) during maturity", Journal of Food Composition and Analysis, 22(7-8), 663-667.

Cid-Ortega, S., \& Guerrero-Beltrán, J. (2015). "Roselle calyces (Hibiscus sabdariffa), an alternative to the food and beverages industries: a review", Journal of Food Science and Technology, 52(11), 6859-6869.

Damiani, E., Bacchetti, T., Padella, L., Tiano, L., \& Carloni, P. (2014). "Antioxidant activity of different white teas: Comparison of hot and cold tea infusions", Journal of Food Composition and Analysis, 33(1), 59-66.
Damiani, E., Carloni, P., Rocchetti, G., Senizza, B., Tiano, L., Joubert, E., de Beer, D., \& Lucini, L. J. A. (2019). "Impact of Cold versus Hot Brewing on the Phenolic Profile and Antioxidant Capacity of Rooibos (Aspalathus linearis) Herbal Tea", Beverages, 8(10), 499.

Faraji, M. H., \& Tarkhani, A. H. (1999). "The effect of sour tea (Hibiscus sabdariffa) on essential hypertension", Journal of Ethnopharmacology, 65(3), 231-236.

Ismail, A., Ikram, E. H. K., \& Nazri, H. S. M. (2008). "Roselle (Hibiscus sabdariffa L.) seeds nutritional composition protein quality and health benefits", Food, 2(1), 1-16.

Lantano, C., Rinaldi, M., Cavazza, A., Barbanti, D., \& Corradini, C. (2015). "Effects of alternative steeping methods on composition, antioxidant property and colour of green, black and oolong tea infusions", Journal of Food Science and Technology, 52(12), 8276-8283.

Leyva Daniel, D. E., Barragan Huerta, B. E., Vizcarra Mendoza, M. G., \& Anaya Sosa, I. (2013). "Effect of drying conditions on the retention of phenolic compounds, anthocyanins and antioxidant activity of roselle (Hibiscus sabdariffa L.) added to yogurt", International Journal of Food Science \& Technology, 48(11), 2283-2291.

Lin, T.-L., Lin, H.-H., Chen, C.-C., Lin, M.C., Chou, M.-C., \& Wang, C.-J. (2007). "Hibiscus sabdariffa extract reduces serum cholesterol in men and women", Nutrition research, 27(3), 140-145.

Mahadevan, N., \& Kamboj, P. (2009). "Hibiscus sabdariffa Linn.-an overview".

McKay, D. L., Chen, C. O., Saltzman, E., \& Blumberg, J. B. (2009). "Hibiscus sabdariffa L. tea (tisane) lowers blood pressure in prehypertensive and mildly hypertensive adults", The Journal of nutrition, 140(2), 298303.

Milani, G., Curci, F., Cavalluzzi, M. M., Crupi, P., Pisano, I., Lentini, G., Clodoveo, M. L., Franchini, C., \& Corbo, F. (2020). "Optimization of Microwave-Assisted 
Extraction of Antioxidants from Bamboo Shoots of Phyllostachys pubescens", Molecules (Basel, Switzerland), 25(1), 215.

Segura-Carretero, A., Puertas-Mejía, M. A., Cortacero-Ramírez, S., Beltrán, R., AlonsoVillaverde, C., Joven, J., Dinelli, G., \& Fernández-Gutiérrez, A. (2008). "Selective extraction, separation, and identification of anthocyanins from Hibiscus sabdariffa L. using solid phase extraction-capillary electrophoresis-mass spectrometry (time-offlight/ion trap)", Electrophoresis, 29(13), 2852-2861.

Sinela, A., Rawat, N., Mertz, C., Achir, N., Fulcrand, H., \& Dornier, M. (2017). "Anthocyanins degradation during storage of Hibiscus sabdariffa extract and evolution of its degradation products", Food Chemistry, 214, 234-241.

Spigno, G., \& De Faveri, D. (2009). "Microwave-assisted extraction of tea phenols: a phenomenological study", Journal of Food Engineering, 93(2), 210-217.

Sun, Y., Liao, X., Wang, Z., Hu, X., \& Chen, F. (2007). "Optimization of microwaveassisted extraction of anthocyanins in red raspberries and identification of anthocyanin of extracts using high-performance liquid chromatography-mass spectrometry", European Food Research Technology, 225(34), 511-523.

Tontul, I., \& Topuz, A. (2017). "Effects of different drying methods on the physicochemical properties of pomegranate leather (pestil)", LWT, 80, 294-303.

Tsai, P.-J., McIntosh, J., Pearce, P., Camden, B., \& Jordan, B. R. (2002). "Anthocyanin and antioxidant capacity in Roselle (Hibiscus sabdariffa L.) extract", Food research international, 35(4), 351-356.

Yang, Z., \& Zhai, W. (2010). "Optimization of microwave-assisted extraction of anthocyanins from purple corn (Zea mays L.) cob and identification with HPLC-MS", Innovative Food Science \& Emerging Technologies, 11(3), 470-476.
Zannou, O., Kelebek, H., \& Selli, S. (2020). "Elucidation of key odorants in Beninese Roselle (Hibiscus sabdariffa L.) infusions prepared by hot and cold brewing", Food research international, 133, 109133. 